\title{
Analysis and Prioritization of Moral Education Injuries in the Family: Case Study of Khash City
}

\author{
Esaq Bameri \\ Academic Staff in Department of Law, University of Sistan and Baluchestan, Zahedan, Iran \\ eshghbameri@gmail.com
}

\section{Doi:10.5901/mjss.2016.v7n5p132}

\section{Abstract}

Training and education have various aspects that moral education is one of the most important of its field. But in this field, extensive qualitative and quantitative scientific studies are required. Especially in our society it is essential that the authorities, by introducing a model of ethical norms and moral defects recognition, recognize ways of prevention and treatment of this problem the goal of present article is, analysis and Prioritization of moral education injuries in the family using AHP model (case study of Khash). The research method is analytic - descriptive and AHP model is used for analysis of data. The result shows that: Index of Lack of family commitment to ethical values $(E)$ with standard weight of (0.282) is in first place and Index of Conflict and diversity of media information $(B)$ with standard weight of $(0.154)$ is fifth place.

Keywords: Training, Moral, Traumatic factors, Khash City, AHP model

\section{Introduction}

Moral education has dedicated a significant part of our educational programs and activities to the next generation. At the same time, this field of training as other aspects can also interfere in other damages of process. Moral education is one of the greatest expectations of an educational system, an expectation which is always felt on it (Ahmadi, 2001). Basically every community to continue to live and explain what is significant and what moral norms should be dominated, it needs principles and logical response program. The thinkers pay always great attentions to understand the moral qualities of life and the role of education in improving their institutions. Moral values have influence on the life of everybody, so that it can be said: Purpose, content and training methodology are expressed on them. Unfortunately, despite the importance of ethics in life and despite the fact that moral education is known as the worthy education of the present century, in recent years this dimension of training has undergone a dramatic transformation (Haghighat and Mazidi, 2008).

Family as the first place where each person will be in it has a remarkable importance. Family atmosphere is the first place where the person receives atmospherically impacts and the influence of other atmosphere can be derived from this atmosphere. Family is the founder of an important part of human destiny and plays a major role in life style and future policy, ethics, health and function of person in future. There are factors such as Parents character, their mental and physical health, educational methods applied in the family, job and education, cultural and economic status of the family, the family residence, family size and population, family and social relations in the family and an infinite number of variables in the family that affects Child's personality, his mental and physical health, career, educational, economic, social and cultural adaptation, family formation, etc. Human should try to look like their morals and their intimate character pretty good. Moodiness is an unacceptable attribute that makes human's life sobering, and in the family environment can exert a negative effect and appears in the form of irritability, cramps face, bored, angry and pernickety that can be said immorality in general and is one of the destructive damages for families.

Destruction of the human personality, creating fear and anxiety, decline of Love, suspicion and distrust and family dispute are considers as the serious impact of this injury.

Moral hazard is considered as the largest and the most deadly injury of family and this damage causes resentment and isolation of family and misadjusts the evolution of family and follows plenty of earthy and hereafter consequences, the earthy consequences are such as: Dreadful life, anxiety, loneliness, decay of faith and practice, deprived of the attention away from God and Hereafter consequences are: Pressure of the grave and death in the depths of hell . It can be concluded that there are six institutions that is effective in shaping a person's character and identity: They are: Community, family, individual, peer, school and religion, training because of involving three dimensions of human existence namely the cognitive, emotional and behavioral development to achieve the ultimate goal of ensuring the 
welfare and integrity of creation, has a significant importance and recognition of disturbing factors of this coordinated and comprehensive training is necessary (Bennet, 1993).

\section{Theory}

\subsection{A look at the causes of traumatic factors}

\subsubsection{Violence and strict}

Relationship full of anger is against relationship full of love. In the past violence was considered as one of educational methods; But this method is not approved by Islam and education scientist and Psychologist. Ibn Khaldun says "if instructor uses violence against student, he is accustomed to violence, too. And pleasure of his soul will disappear and will be boredom and isolation, and harbor in lies and falsehood, and fears if he doesn't treat in such a way, others will take on him and subdues him. This is why the student will be familiar with deception and cheating and found his work on this incorrect approach. It deserves to teachers and parent not to treat in violence in training their students and in upbringing their children but they should treat softly (Shamlo, 1999, 115).

\subsubsection{Lack of family commitment to ethical values}

Several factors can be effective on the behavior of the children, adolescent and young people through the family. these factors can be traumatic and the more traumatic the more negative effect of family on the character of the person. In treating of family with adolescents and young people, Psychologists refer to four categories:

Liberal families: they give freedom to teen in choice, however assign responsibilities to him and want him to consider values and laws and do not violate the rights of others. Such families in addition to maintaining their ability, show attention to teen demands and play a guiding role.

Inconsiderate families: give complete freedom to teens and has no control on him and don't guide him and also don't know his friends and retailers. Because these families are too busy, they are ignorant of their children or they have a sense of negligence and carelessness.

Strict and authoritarian families: refusal to respond to the needs of the young is this family's style. This leads adolescents to practice behaviors that parents hated to do. Lying, malice and fleeing from the school are more in these families. A father that knows his son as a slave and obliged him to observe things which its philosophy and reason are not clear to him or in on other words, they don't justify their children acts and behaviors emotionally and rationally, In fact, it will hurt his self-esteem. Such a child will be inactive in future, pusillanimity in social behavior and aimless in the execution of the will of the Divine commandment and will be swift and daring in committing sins (Bihar, v 23, 114).

\subsubsection{Conflict and diversity of media information}

Among the mass media and new technologies, television, computer and in some families, satellite have the greatest influence on young minds, despite the positive outcomes for families and communities in some aspects, they have raised some issues such as the pale of moral values, cultural and moral damages and the norm breaking.

Statistics show that in the United States, children has amused by T.V in families in such a way that they pay more attention to watching T.V than going to school. Before they reach the age of 18 , they have seen and heard approximately 200 million acts of violence and 14 thousand of sexual messages.

In our country, despite the attention of the authorities to provide low-risk programs on television, the damage of this educational factor is significant. Children and adolescents have an active relation with this phenomenon. The role of television advertising or training may be seen more, but is extremely helpful in shaping human behavior especially in young people. One of the most damaging aspects of television which it may be universal is, the effects of television violence on the thoughts, beliefs, feelings and behavior of children and young people in particular that provide a variety of antisocial and unethical behavior such as: Beating, insulting, threatening, throwing of objects, humiliate others, brutality and defiant against the rules of moral and social rules and dozens of other injuries.

\subsubsection{Economic and social Inequalities}

Class differences places people especially, the young, in a situation that they can't find their appropriate social roles and 
responsibilities, and this can lead to anti-social behavior and immoral.

Each of social classes has their specific values, norms, beliefs and lifestyles. Difference between social classes can be led to specific behaviors conflict. Family's poverty and injustice in providing similar services to citizens lead to the formation of severe anomie. Imam Ali says: Poverty is a source of moral corruption.

Economy condition, the welfare and poverty, both are traumatic factors in moral education. Those who live in a family that have the minimum possibilities for meeting their needs are optimistic and less anxiety, less pessimism and lack of confidence.

\subsubsection{Bad friends}

Another important factor in damaging moral education is wrong friends and peers. Joining to groups, especially group of friends can have both destructive and useful effects. Group gives privilege and comfort to the teen and encourages him in constructive and useful activities. In the group, rules, cooperation and respect for the rights of others will be trained. The need of young and teenagers to group causes that he comply his whole behavior with their demands and leave behaviors that lead to the Banishment. This result is observed in positive, good and valuable groups. But the teenagers may be misled by involving in deviant groups; because in these cases, the person are effected by emotions and don't evaluate the people with reality; for example, if a person has certain physical strength and as a leader among peers use techniques and methods of absorption, but has not positive features of moral and social, the group behavior effected by him will be disturbing, aggression and bullying.

\subsection{The importance and purpose of education from the perspective of experts}

Studying of different views shows that the goal of training is achieving personal excellence and prepare people for healthy and thriving presence in the community. Frobel, German scientist (1852) not only believes that training is "development of hidden forces that nature has given to the child", but also believes" in raising the child for social life" and emphasized the social purpose. Jean Piaget believes that the main goal of education is "the full blossoming of human personality and respect for human rights and respect for fundamental freedoms". But among the elite of west education, scientists such as " Rousseau"," Pstalzy","Kant" and " Hrbart" pay a special attention to "human training in ethical dimension" (Dehshiri, 1991,25).

Kant believes that" Solving the most difficult problem of education is the responsibility of moral education and, man by education and training can only be "Human". Reforming of moral must be part of the training and qualifications of the individual for his training is not enough. Only good trends should be developed in him. He says " we are living in the age of discipline, culture and civilization but still have not reached the age of moral education, so for moral education, character should be developed that its main aspects are: Obedience, honesty and good socializing" he believes that holiness and moral excellence is very important and says we should not decrease the diminishing of moral by putting it in line of discipline (Kant,1984, 47,48, 72) (Pakseresht, 2001).

\section{The Scope of the Studying Region}

The city of Khash is one of the cities of Sistan-Baluchestan province of Iran and is located in the South East of Iran and its distance to the center of the province (Zahedan) is $175 \mathrm{~km}$. This city is located at eastern longitude of 60 degrees, 55 minutes and 61 degrees 30 minutes and at northern latitude of 27 degrees 50 minutes and 28 degrees 40 minutes and it is located in a smooth plain directed from the north-west to south-east and the mountains of Panjangosht are located in the west of the city and the heights of Dahana, the valley of Amr, Zirok are located in the East and Northeast of the city. The peak of Taftan is located near the city in northern part of the city. This city has 2 urban centers, 3 counties, 11 districts, 799 villages and it includes 4 area and 14 regions. 


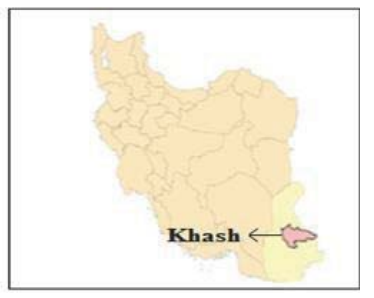

Figure (1): The area under study, Source: search results

\section{Materials and Methods}

The research, applied research, analytical and descriptive method and based on documents and field studies, library and more. And AHP model was used for data analysis.

\section{Discussion and Conclusions}

First, the problems of converting a hierarchical structure that includes a three-level hierarchy of objectives, criteria, and be choices.

Table 1: Indicators of injuries moral education in the family

\begin{tabular}{|l|c|}
\hline Violence and strict & A \\
\hline Conflict and diversity of media information & B \\
\hline Economic and social Inequalities & C \\
\hline Bad friends & D \\
\hline Lack of family commitment to ethical values & E \\
\hline
\end{tabular}

Source: Research Findings

Comparison matrix to determine the binary parameters $(A=$ aij $)$ question are results and their importance and expertise of specialists in this field is used.

Table (2): Matrix A couple of indicators

\begin{tabular}{cccccc}
\hline E & D & C & B & A & Indicators \\
\hline 3 & 1.2 & 2 & 1.2 & 1 & A \\
\hline 1.6 & 1.8 & 1.3 & 1 & 1.2 & B \\
\hline 3 & 2 & 1 & 1.2 & 2 & C \\
\hline 3 & 1 & 1.7 & 1.6 & 1.2 & D \\
\hline 2 & 3 & 2 & 4 & 1.6 & E \\
\hline 12.6 & 9 & 8 & 9 & 7 & $\mathbf{\Sigma}$ \\
\hline
\end{tabular}

Source: Research findings

Matrix pair (two for binary) index is obtained as follows:

It is to fill this matrix; scale of 1 to 9 is used to determine the relative importance of each element relative to other elements.

Table (3): 9 Saaty scale quantitative comparison of binary options

\begin{tabular}{|c|c|c|c|c|c|c|}
\hline Intensity of importance & 1 & 3 & 5 & 7 & 9 & $2-4-6-8$ \\
\hline Definitaion & $\begin{array}{l}\text { Equal } \\
\text { importance }\end{array}$ & $\begin{array}{l}\text { Weak importance of } \\
\text { one over another }\end{array}$ & $\begin{array}{l}\text { Essential of } \\
\text { strong importnace }\end{array}$ & $\begin{array}{l}\text { Demonstrated } \\
\text { importance }\end{array}$ & $\begin{array}{l}\text { Absoloute } \\
\text { importance }\end{array}$ & $\begin{array}{l}\text { Intermediate } \\
\text { values }\end{array}$ \\
\hline
\end{tabular}

Source: Research findings 
After forming the matrix of paired comparisons and values should be the norm. For this purpose, the value of each column of the matrix corresponding to the sum will be divided.

Table (4): Paired comparison matrix normalized relative indicators and weights

\begin{tabular}{cccccc}
\hline E & D & C & B & A & Indicators \\
\hline 0.238 & 0.133 & 0.25 & 0.133 & 0.142 & A \\
\hline 0.126 & 0.2 & 0.162 & 0.111 & 0.171 & B \\
\hline 0.238 & 0.222 & 0.125 & 0.133 & 0.285 & C \\
\hline 0.238 & 0.111 & 0.212 & 0.177 & 0.171 & D \\
\hline 0.158 & 0.333 & 0.25 & 0.444 & 0.228 & E \\
\hline
\end{tabular}

Source: Research Findings

The logical consistency of judgments

Now the same steps for all choices of $(a, b, c$,$) we do. This step must be calculated to determine whether the$ inconsistency rate between paired comparisons we are compatible or not. Here are just a couple of inconsistency rate for comparisons of account we choices of similar operations to be performed on every indicator. Inconsistency rate can be obtained from the following relationship be:

$$
I . . R .=\frac{I . . I .}{I . I . . R .}
$$

Table (5): Inconsistency rate (IR): the table below is extracted:

\begin{tabular}{|lcccccccccc}
\hline $\mathbf{N}$ & $\mathbf{1}$ & $\mathbf{2}$ & $\mathbf{3}$ & $\mathbf{4}$ & $\mathbf{5}$ & $\mathbf{6}$ & $\mathbf{7}$ & $\mathbf{8}$ & $\mathbf{9}$ & $\mathbf{1 0}$ \\
\hline$I . . I . . R$ & 0 & 0 & $0 / 58$ & $0 / 9$ & $1 / 12$ & $1 / 24$ & $1 / 32$ & 1.41 & 1.45 & 1.45 \\
\hline
\end{tabular}

\section{Source: Research Findings}

So the inconsistency rate calculations in the present study, 0.05 is .Since $I R=0.05$ smaller than $0 / 1$, then the paired comparisons, there is a remarkable consistency All calculations of the eigenvector (eigenvector) is carried out .In the questionnaire, and explain briefly introduce the measure compiled and presented in Table values for comparison of paired preference, paired- comparison was requested to be completed. The sample questionnaire, and program managers are urban planners. After collection, analysis and verification questionnaire, the following results were obtained:

$A(L: 0.179), B(L: 0.154), C(L: 0.195), D(L: 0.181), E(L: 282)$

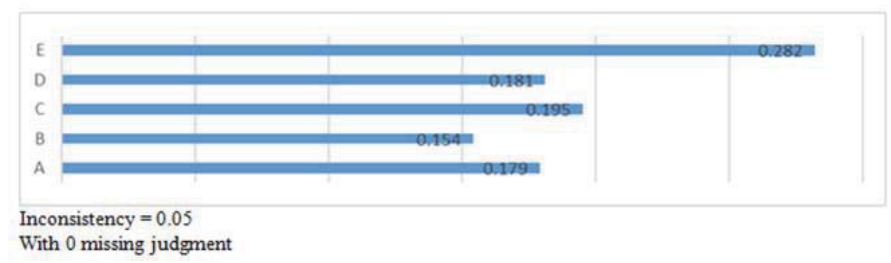

Figure (2): Results of hierarchical analysis using expert choice software, Source: research findings

Table (6): Final ranking injury indicators moral education in the family

\begin{tabular}{clcc}
\hline Indicators & Criterion & Weight & Rank \\
\hline A & Violence and strict & 0.179 & 4 \\
\hline B & Conflict and diversity of media information & 0.154 & 5 \\
\hline C & Economic and social Inequalities & 0.195 & 2 \\
\hline
\end{tabular}




\begin{tabular}{llll}
\hline D & Bad friends & 0.181 & 3 \\
\hline E & Lack of family commitment to ethical values & 0.282 & 1 \\
\hline
\end{tabular}

Source: Research Findings

The result of analysis of AHP model shows that:

* Index of Lack of family commitment to ethical values $(E)$ with standard weight of $(0.282)$ is in first place.

* Index of Economic and social Inequalities (C) with standard weight of (0.195) in second place.

* Index of Bad friends (D) with standard weight of (0.181) in third place.

* Index of Violence and strict (A) with standard weight of (0.179) in fourth place.

- Index of Conflict and diversity of media information (B) with standard weight of $(0.154)$ is fifth place.

\section{Conclusion}

The final word is that children will be affected by values, norms and attitudes of coaches and parents who represent the society and also will be affected by the all ways and styles which are interacted. So families can have a positive effect on social and ethical judgments of children by providing opportunities to discuss and decide on issues such as ethical, social and moral stimulation of cognitive abilities, correct behavior in the eyes of children, respect for children and providing opportunities for children to experience the moral. Obviously, moral maturity of teachers and parents is one of the major factors that affect the quality of the relationships. On the other hand, the ultimate goal of moral education is closeness to God that the ultimate goal will give confidence, earthly happiness and eternal peace to the mankind and intermediate goals which is leaving the vices and practicing to virtues. Contemplation is one of the intermediate objectives. However the environment of human is one of intermediate goals which help people to reach the final goal which is Rizwan Elahi (the closest place to God). Moderation is a principle helps human in all the virtues and ethical statements.

The goal of present article is, analysis and rating of moral education injuries in the family using AHP model (a case study of Khash). The result of analysis of AHP model shows that: Index of Lack of family commitment to ethical values (E) with standard weight of $(0.282)$ is in first place and Index of Conflict and diversity of media information (B) with standard weight of $(0.154)$ is fifth place.

\section{References}

Ahmadi, S. A., (2001), Principles of education in Islam, Isfahan, Isfahan University Press.

Bennet,W,J., (1993), TheBook of Virtues:A Treasury of Great Moral Stories, New york: Simon and Schuster.

Dehshiri, A, S., (1991), Moral Education, Research Department, Tehran. vol 23, p 114

Haghighat, Sh B, Mazidi, M, (2008), Evaluation of four methods of teaching philosophy and approach to the field of contemporary moral education, Journal of Religious Thought, No. 26, University of Shiraz.

Kant, I, (1984), Education", translated by Golam Houssin, Sh, pp. 47, 48, 72 and 128 ps.

Paksrsht, MJ, (2001), philosophical schools and educational opinions, Author: Gerald, G, Tehran.

Shamli, A A, (2000), in an attempt to achieve a model of moral education moral education in Islam (Book II), Tehran: Press deputy education.

Shamlo, S., (1999), mental health, development Publications, Tehran, The Holy Quran 


\title{
The Main Problems and the Role of Teachers in the Transformation of Education in Serbia
}

\author{
Marko Atlagic \\ The University of Mitrovica, Faculty of Philosophy, Serbia; atlagicmarko@gmail.com
}

Zvezdana Elezovic

Institute of Serbian Culture Leposavic, Serbia; zvezdana.el@gmail.com

Vesna Minic

The University of Mitrovica, The Faculty of Teacher Education, Serbia; vesna.minic@pr.ac.rs

\section{Doi:10.5901/mjss.2016.v7n5p138}

\section{Abstract}

This paper discusses the issue of the reform of education in the Republic of Serbia, which should be carried out on democratic grounds. The authors advocate the transformation of the entire education system on democratic grounds. The reform has to be fast, thorough, and democratic. The teacher has to play the central role in this strategic plan. Therefore, the role of the teacher should be transformed from an indifferent or authoritarian teacher into one with a democratic approach, who will cooperate with students in the planning, execution, and implementation of the educational process. For this role of teachers, it is necessary to utmostly improve his/her professional and pedagogical development.

Keywords: education, teacher, pedagogue, reform

\section{Introduction}

In the past half century, many reforms have come and gone. Each of them left, among other things, a positive sign, brought changes, but there has been only few reforms whose strategy was carefully designed, and even a smaller number of those that were fully implemented. None of them has been able to be, in a true sense, democratic, educational, and scientifically based (Strategy, 2012). Moreover, no reform, to date, has managed to solve the problem of adequate financing of this very important activity. Regardless of it, education has become, more or less, a generator of the progressive development of society (Pastuovic, 2012).

Pedagogical sciences were late, and are late today as well, in providing answers to many open pedagogical questions, both those from the domain of the concept of the education system, and those within the scope of its internal organization. Therefore, the reform of education must be entered into democratically, scientifically based, and very courageously, and without hesitation. The reform must be democratic, radical, and comprehensive. In the first phase of implementation, the reform should include faculties of education and other faculties. Then economic and educational prerequisites should gradually be created for a reaffirmation of the educational role of the school and society, especially the pedagogical profession, which has been neglected in the last two decades in the Serbian society. The pedagogical institutes and faculties of education should not be excluded from making the concept and implementing the reform of education. Never has it been more necessary than today to face the social and pedagogical reality, to critically reexamine our experiences, without any overestimation or underestimation of any model of education. Never has it been more necessary than today to affirm the system of permanent professional and pedagogical training of education workers (Exposé, 2014). First of all, we need a rebellion of truth about the state of Serbian educational system, because we can no longer leave students on an educational astray.

\section{Method}

Our research on the subject of this scientific work belongs to the fundamental or basic research dealing with the study of 